Original Article

\title{
FLORAL PHENOLOGY, NECTAR SECRETION DYNAMICS, AND HONEY PRODUCTION POTENTIAL, OF TWO LAVENDER SPECIES (LAVANDULA DENTATA, AND L. PUBESCENS) IN SOUTHWESTERN SAUDI ARABIA
}

\author{
Adgaba Nuru* \\ Ahmad A. Al-Ghamdi \\ Yilma T. Tena \\ Awraris G. Shenkut \\ Mohammad J. Ansari \\ Anwer Al-Maktary
}

Engineer Abdullah Bagshan Chair for Bee Research, Department of Plant Protection, College of Food and Agricultural Science, King Saud University Riyadh 11451

Riyadh (P. Box 2460), Saudi Arabia

*corresponding author: nuruadgaba@gmail.com
Received 18 August 2015; accepted 07 October 2015

\begin{abstract}
The aim of the current study was to determine the floral phenology, nectar secretion dynamics, and honey production potentials of two naturally growing lavender species (L. dentata and L. pubescens), in southwestern Saudi Arabia. In both species, flowering is continuous. This means that, when open flowers on a spike are shaded, new flowers emerge. Such a flowering pattern might be advantageous to the plant to minimise competition for pollinators and promote efficient resource allocation. The flowering periods of the two species overlap. Both species secreted increasing amounts of nectar from early morning to late afternoon. The mean maximum volumes of accumulated nectar from bagged flowers occurred at 15:00 for $L$. pubescens $(0.50 \pm 0.24 \mu \mathrm{L} /$ flower) and at 18:00 for $L$. dentata $(0.68 \pm 0.19 \mu \mathrm{L} /$ flower $)$. The volume of the nectar that became available between two successive measurements (three-h intervals) varied from $0.04 \mu \mathrm{L} /$ flower to $0.28 \mu \mathrm{L} /$ flower for $L$. pubescens and from $0.04 \mu \mathrm{L} /$ flower to $0.35 \mu \mathrm{L} /$ flower for $L$. dentata, This variation reflects the differences in the dynamics of nectar secretion by these species, and indicates the size of the nectar that may be available for flower visitors at given time intervals. The distribution of nectar secretions appears to be an adaptation of the species to reward pollinators for longer duration. Based on the mean amount of nectar sugar secreted by the plants, the honey production potentials of the species are estimated to be $4973.34 \mathrm{mg}$ and $3463.41 \mathrm{mg}$ honey/plant for L. dentata and $L$. pubescens, respectively.
\end{abstract}

Keywords: flower morphology, flowering period, lavandula, nectar secretion, Saudi Arabia.

\section{INTRODUCTION}

The majority of lavender species are indigenous to the mountainous regions of the western Mediterranean countries, the islands of the Atlantic, Turkey, Pakistan, and India (Chu and Kemper, 2001). Moreover, they are native to northern, eastern, and southern Africa, the Arabian Peninsula, Bulgaria, and Russia (Boning, 2010).

Lavender species survive, and can thrive, in arid and semi-arid regions of the world, even in areas threatened by desertification (Azcón and Barea, 1997). It is known as extremely drought resistant once established. Species of lavender prefer gravelly, slightly alkaline and limestone-based soils (Boning, 2010). Certain species (Lavandula dentata and $L$. pubescens) have a thick branching from the base. This branching makes them useful in soil erosion control.

Today, lavender species are extensively cultivated throughout the world, particularly in France, Bulgaria, Russia, Italy, Spain, England, the USA, and Australia (Lalande, 1984; Boning, 2010). These plants are grown commercially for the extraction of their essential oils, which are used in perfumery, in cosmetics, as ingredients in numerous cottage 
industry products, in food processing, as massage products, as culinary herbs, and as ornamental plants (Lis-Balchin, 2003). Certain types of lavender oil have also been shown to have antimicrobial and antifungal properties (Chu and Kemper, 2001; LisBalchin, 2003). The plant oils are also widely used in aromatherapy (Welsh, 1995; Lis-Balchin, 2003).

Several species of lavender are visited frequently by honeybees. Where there is dense growth, the plants serve as sources of premium mono-floral honeys with characteristic physical properties. These honeys have a flowery, pleasant, very fine aroma and delicate floral scent with an evident lavender component (Forler, 2013). Numerous countries, including France, Spain, Italy, Bulgaria, England, the former members of the USSR and Yugoslavia, Australia, the USA, Canada, South Africa, and Tanzania are known for the production of lavender honeys (Forler, 2013). Lavender honeys can command a premium price of approximately $\$ 50 / \mathrm{kg}$ in specialty food stores.

In Saudi Arabia, there are five naturally growing lavender species: L. atriplicifolia Benth, L. citriodora, L. coronopifolia Poir., L. stricta Del., L. dentata L., and L. pubescens Decne (El-Karmy and Zayed, 1992; Rahman et al., 2003). The country is known as one of the main geographical areas of lavender species diversity and endemism. Saudi Arabia has been suggested as a center of origin for the genus (Miller, 1985). Uses of L. dentata, L. coronopifolia, L. pubescens, and L. stricta as medicinal plants in Saudi Arabia have been reported (Rahman et al., 2003). Within the country, Lavandula species such $L$. dentata and $L$. pubescens are widely distributed in the mountainous regions of Taif, Albaha, and Asir. These species from the mountainous regions serve as sources of high-quality lavender honeys, locally known as "Seyfi honey," that sell for a premium price of $\$ 50-120 / \mathrm{kg}$.

The majority of the studies on lavender species have been limited to commercial cultivars, whereas the growth and honey production of the species under their natural conditions, particularly in the semiarid areas of the Arabian Peninsula remain unaddressed. The natural occurrence of multiple lavender species in the region and their remarkable ability to withstand extreme drought conditions is known. However, their ecological and socio-economic values, floral biology, nectar secretion dynamics, and honey production potentials have not been documented.

Based on detailed studies on the dynamics of nectar secretion, including the amount and its sugar con- centration, it has been possible to estimate the honey production potentials of several important honey source plants, e.g., Asclepias syriaca L. (500 - $600 \mathrm{~kg}$ honey/ha/flowering season) (Zsidei, 1993), Trifolium pretense L. (883 kg of sugar/ha/flowering season) (Szabo and Najda, 1985), and Phacelia tanacetifolia Benth (60 - $360 \mathrm{~kg}$ honey/ha/flowering season) (Nagy, 2002). Moreover, Crane et al. (1984) reported the honey production potential of different lime species (Tilia spp.) ranges from 90 to $1200 \mathrm{~kg}$ honey/ha. Recently, Kim et al. (2011) quantified the amount of nectar secreted per flower and per tree for Crataegus pinnatifida Bunge. The amount and dynamics of nectar secretion have been used, as well, to estimate the honey production potential of Ziziphus spina-christi (Nuru et al., 2012). In this general context, the aim of the current study was to determine the floral phenology, nectar secretion dynamics, and honey production potentials of the two, major, naturally growing Lavandula species (L. dentata, and L. pubescens) which are used as important sources of honey in regions of southwestern Saudi Arabia.

\section{MATERIAL AND METHODS}

\section{Study site and species description}

The study was conducted in the area of Baljurashi, Al-Baha region, Saudi Arabia, at 1952'06.819" N and $41^{\circ} 36^{\prime} 48.218^{\prime \prime} \mathrm{E}$, at 2050 meter above sea level. The study area is categorised as being under the highland physiographic and climatic conditions. The humidity ranges from $52 \%$ - 67\%. The rainfall ranges from 229 - 581 mm/annum. The mean temperature is $22.9^{\circ} \mathrm{C}$ (Al-Baha Meteorological Station, 2012). The studied species mainly grow on gentle to steeply sloping lands in shallow, rocky, limestonebased soil types (Fig. 1 A and B). The plants, in some locations, occur as the dominant vegetation type while in other sites grow in association with various species, such as Olea chrysophylla Lam., Juniperus procera Hochst., Psiadia punculata (DC.) Vatke., Dodonaea angustifolia L.f., Maytenus spp., and Acacia origena Asfaw. Both L. pubescens and L. dentata grow naturally with almost overlapping distributions under the same environmental conditions. Lavandula dentata is a much branched, bushy, shrub type up to $75 \mathrm{~cm}$ tall. The leaves are aromatic, sessile, and linear, up to $35 \mathrm{~mm}$ long, $3 \mathrm{~mm}$ wide with strongly curved edges. The inflorescences are dense with a terminal spike up to $7 \mathrm{~cm}$ long. Lavandula pubescens is also a densely-spreading perennial herb, up to a meter tall. The branches are 

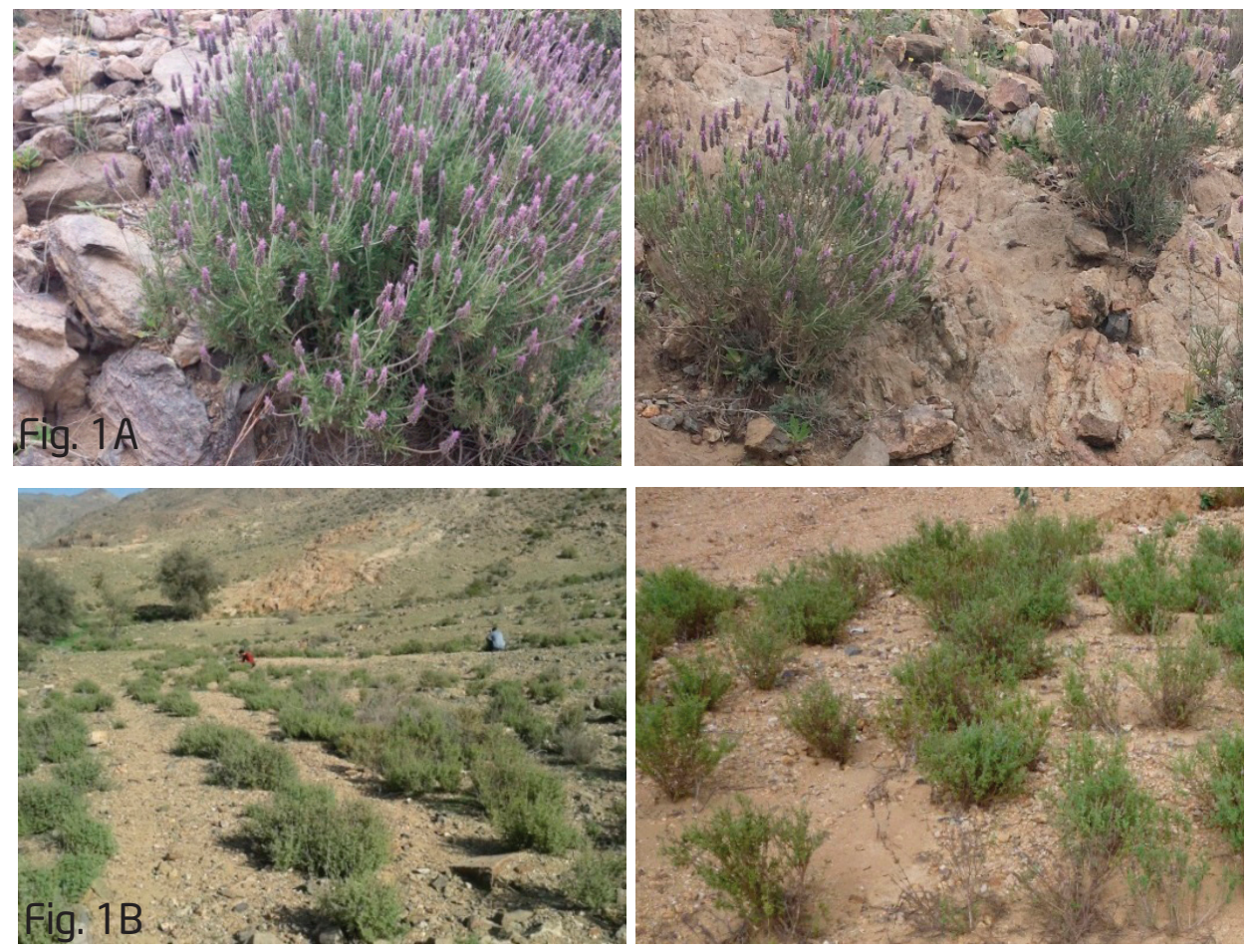

Fig. 1. A. Lavandula dentata and Fig.1, B. Lavandula pubescens with their growing habitats.

glandular-pubescent. The leaves are petiolate, and deeply dissected into short, oblong-linear lobules. The inflorescences are dense, with branched or unbranched terminal spikes. Both species are characterised by their remarkable adaptation to long dry periods via the suppression of their physiological activity. During a dry period, both the leaves and spikes look completely dry, however, when there is sufficient moisture, they rapidly resume their growth and produce numerous new young shoots and flowering buds.

\section{Floral and plant morphological features}

The morphological features of the flowers, such as the shape of flower parts and their arrangements were observed and described. Moreover, the number of flower lobs and the depth of the corolla tubes were characterised by measuring 10 flowers per plant and 50 flowers/species.

The mean length and number of spikes per plant were determined by counting all spikes from 20 L. pubescens plants and 10 L. dentata plants. The mean number of flowers per plant was obtained by counting the mean number of spikes per plant and multiplying by the mean number of flowers/spike. The mean number of flowers/spike was obtained by counting the flowers in 51 and 76 spikes of $L$. dentata and $L$. pubescens, respectively. In addition to the floral features, the plant morphological features, such as: plant height, crown height, and crown diameter were determined by measuring 63 and 47 individuals of L. dentata and L. pubescens, respectively.

\section{Flower phenology and flowering period distribu- tion}

To determine the phenology of flowers, three individual plants per species were labeled. From each plant, eight mature flower buds/day were marked in the late afternoon to be monitored the following day. When marking, all of the previously opened flowers from the spike were carefully removed to prevent confusion. On the next morning, development of flower buds was monitored every $2 \mathrm{~h}$ from 06:00 to 18:00. The observations were replicated for three consecutive days (a total of 72 flowers/species). The time of flower opening and flower abscission, and the life span of a single flower were recorded.

The flowering period patterns (commencement, peak, and end) and total duration of flowering were determined by monitoring and recording the flowering periods for each species. For this purpose, a proportional sampling was performed; 20 and 10 individual plants of $L$. pubescens and $L$. dentata, respectively, were selected and labeled before the commencement of flowering. During selection, an effort was made to choose plants representative of differing land gradations (flat, gently sloped, and 
steeply sloped lands), ages, and branching conditions. For each labeled plant, the number of shoots (spikes) that initiated flowering was recorded every week from the commencement of flowering until the end of flowering. The peak flowering was considered as the time when more than $50 \%$ of the potential flower buds were at the blooming stage.

\section{Amount and dynamics of nectar secretion}

The amount of nectar (in $\mu \mathrm{L}$ ) secreted per flower and its dynamics were determined for a total of six individual plants (three plants/species). The amount of nectar was estimated five times per day at 06:00, 09:00, 12:00, 15:00, and 18:00. The flower buds were bagged a day before opening using bridal-veil netting (Wyatt et al., 1992). From each plant and at each sampling time, the nectar volume was measured in ten flowers (a total of 50 flowers/day/plant). The nectar volume measurement was repeated for three consecutive days (total of 450 flowers/species). Each flower was sampled only once. The volume of nectar contained in the flower was determined by directly removing the nectar using $1 \mu$ capillary tubes (Drummond Scientific Company, USA). Then the volumes of nectar were compared between the species.

\section{Honey production potential}

The honey production potential was estimated by multiplying the mean number of flowers/plant by the mean amount of nectar sugar/flower. The mean mass of sugar in the secreted nectar was calculated from the volume and concentration of the solution. The concentration was measured using a pocket refractometer (ATAGO, No. 3840, Japan). The honey production potential per plant was calculated by multiplying the mean number of spikes per plant by the mean number of flowers/spike and then multiplying by mean nectar sugar/flower following the method described by Kim et al. (2011). These data were used to estimate the honey production potential/plant and to further extrapolate the honey production potential/ha for each species. The estimation of the number of plants per hectare was based on considering the mean canopy diameter of each species, and the space required between plants. For the determination of the mean canopy diameter; 63 and 47 individual plant crown dimensions were measured for $L$. dentata and $L$. pubescens, respectively.

\section{Weather data}

In addition to the above-described observations, weather data such as the temperature, and relative humidity $(\mathrm{RH})$ of the area, were recorded at each sampling time using an Environment Meter (NO9AQ, UK).

\section{Statistical analyses}

One-way ANOVA t-test and f-test results were computed to compare the means between the species and among the times of day, respectively. Two-way ANOVA was employed to determine the effect of the interaction between the time of a day and species. Correlation and regression analyses were performed to explore the relationship of nectar secretion with the morphological and weather condition parameters. For the analyses, the JMP-5 statistical software (SAS, 2002) was employed.

\section{RESULTS}

\section{Flower morphology and arrangement}

The flowers of $L$. pubescens arise from an elongated spike that varies from 4.6 to $18.0 \mathrm{~cm}$ in length, with a mean length of $9.7 \mathrm{~cm}$ (Fig. 2). Some of the spikes are branched and a single spike contains, on average, 64.0 flowers. The corolla are deep blue and are bilabiate, with the upper lip 2-lobed and the lower 3-lobed. The total length of the corolla varies from 10.0 to $15.0 \mathrm{~mm}$, with a mean of $12.6 \mathrm{~mm}$, of which, approximately 8 - $10 \mathrm{~mm}$ forms the corolla tube. The pistil is bicarpellate, and the branches of the style are flat. There are 4 didynamous stamens concealed in the corolla tube; the anterior pair is longer. The anthers are located $2-3 \mathrm{~mm}$ below the mouth of the corolla tube.

The inflorescence in L. dentata (Fig. 3 ) is dense with a terminal spike. The length of the spike ranges between 3.5 and $6.2 \mathrm{~cm}$ (mean of $4.5 \mathrm{~cm}$ ). A single spike contains, on average, 91.0 small flowers. The corolla is bilabiate, with a 5-lobed limb. The corolla tube is about $4-5 \mathrm{~mm}$ in depth. The total length of the corolla varies between 6 and $9 \mathrm{~mm}$ (mean of 7.6 $\mathrm{mm}$ ). There are four didynamous stamens concealed in the corolla tube; the anterior pair is longer. The pistil is bicarpellate, and the branches of the style are flat.

\section{Flower phenology and flowering period distribu- tion}

From the 72 total flower buds marked per species, 63 and 59 for $L$. pubescens and $L$. dentata, respectively, were observed to open at 06:00. These observations indicate that in both species, the peak opening time is early morning. All of the remaining flowers from both species opened by 10:00. From 
16:00 to 18:00, 65 of the L. pubescens and 57 of L. dentata labeled flowers wilted and dropped their petals. The remaining few flowers lasted up to 18:00. These observations indicate that a single flower generally stays for less than one day. Between 12:00 and 18:00, a number of new flowers were observed to open from buds other than the labeled ones, indicating that, in both species, the opening of flowers is continuous. This means, that when 5 - 7 previously opened flowers/spike shade off, about the same number of new flowers/spike sequentially open with a certain degree of overlapping among individual flower-opening times. Hence, the time of flower opening is not restricted within a day.

Although the two species grow under the same ecological conditions, there was a slight difference in the timing of flowering. Plants of $L$. pubescens started to flower slightly earlier than those of L. dentata. Lavandula pubescens begins flowering in winter in mid-December. The species continues to flower throughout January and March, with peak flowering occurring in February. Flowering ends after the first week of March; the flowering lasts for about 80 days.

Lavandula dentata starts and finishes flowering relatively later in the season than $L$. pubescens. Lavandula dentata starts flowering in the first week of January, attaining its peak between the second
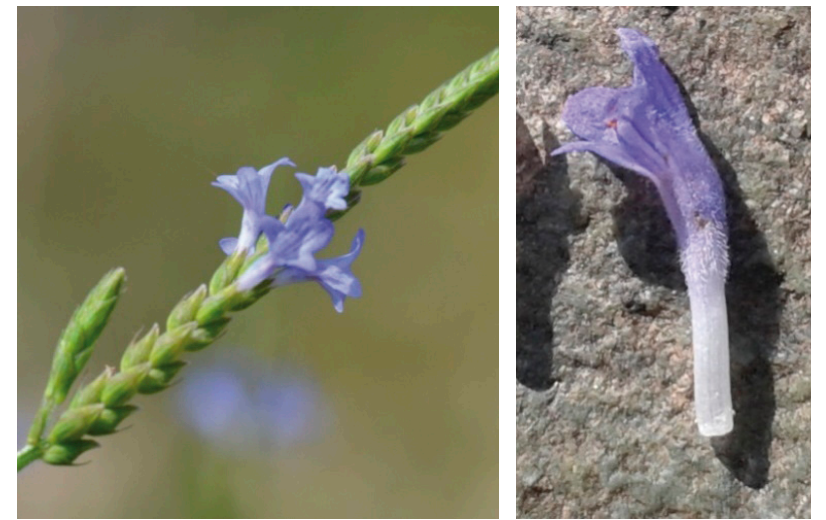

Fig. 2. Floral morphology of the spike (left) and corolla (right) of $L$. pubescens.

week of February and the first week of March. The plants continue flowering until the third week of March, and flowering ends at the end of March, indicating that $L$. dentata exhibits an extended flowering period lasting for about 90 days. The peak flowering periods of the two species were observed to overlap for about 70 days from the $1^{\text {st }}$ week of January up to the $1^{\text {st }}$ week of March. In both species when there is lack of soil moisture, the buds on the spike stop growing and flowering, but when there is sufficient rainfall, the buds resume growth and flowering.

\section{Morphometric values of the two species}

The study results show the presence of significant differences in morphological measures (Tab. 1) between the studied species. On average, the plant heights and crown dimensions of $L$. pubescens were $38 \%$ and $33 \%$ lower, respectively, than those of $L$. dentata. However, L. pubescens was significantly $(P<0.003)$ wider in terms of crown diameter than L. dentata. The mean numbers of flower buds per plant were slightly greater in L. dentata than in L. pubescens but not statistically significantly different. The results also revealed the presence of a significant $(P<0.001)$ positive correlation $(r>0.61)$ between the number of flowers and other morphological features, such as plant height, crown height, crown diameter, and crown volume.

\section{Nectar secretion dynamics and volume}

The study results indicate the presence of significant variation $(P<0.001)$ in the mean volume of nectar secreted/flower over the course of the day in both species (Tab. 2). In addition, the total volume of nectar secreted by L. dentata was significantly higher $(P<0.001)$ than that of $L$. pubescence, and
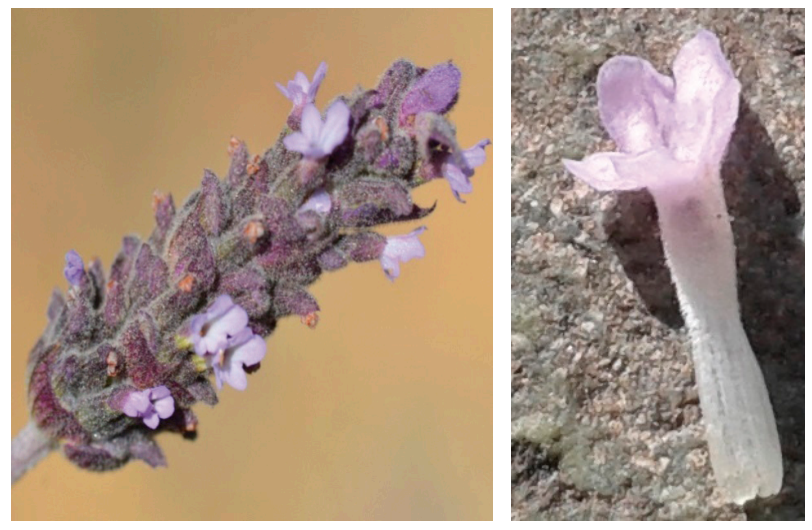

Fig. 3. Floral morphology of the spike (left) and corolla (right) of L. dentata.

the interaction between the time of day and species was significant $(P<0.001)$.

In both species, the period of nectar secretion started in the early morning (06:00) and extended into the late afternoon. The maximum accumulated volumes of nectar were $0.50 \pm 0.24 \mu \mathrm{L} /$ flower and $0.68 \pm$ $0.19 \mu \mathrm{L} /$ flower at 15:00 and 18:00 for $L$. pubescens and $L$. dentata, respectively. Regarding the trends in the amount of nectar secreted, the accumu- 
lated volume increased until 18:00 in the case of L. dentata. A similar trend was noted until 15:00 for $L$. pubescens, but there was a decreasing trend between 15:00 and 18:00 (Tab. 2).

Generally, the mean secreted nectar volume/ flower and the mean maximum accumulated nectar volume/flower at the end of the day were greater in $L$. dentata than in L. pubescence (Tab. 2 ).

The amount of nectar calculated as the difference between two successive measurements $(3 \mathrm{~h}$ intervals) varied from $0.04 \mu \mathrm{L} /$ flower to $0.28 \mu \mathrm{L} /$ flower for $L$. pubescens, and from $0.04 \mu \mathrm{L} /$ flower to $0.35 \mu \mathrm{L} /$ flower for $L$. dentata. These values indicate the variation in nectar secretion of the studied species and their nectar volume that might be available for flower visitors at given time intervals (Tab. 2).

\section{Nectar dynamics in relation to weather conditions} For both $L$. pubescens and $L$. dentata, the amount of nectar per flower significantly increased with an increase in temperature $(P<0.001 ;$ Tab. 3$)$. Moreover, the nectar amount in L. dentata tended to increase $(P<0.004)$ with an increase in relative humidity. However, in the case of $L$. pubescens, though not statistically significant ( $P>0.05)$, the nectar volume tended to decrease with an increase in relative humidity. The highest nectar volumes were recorded at a mean temperature of $35.7^{\circ} \mathrm{C}$ and $28.7 \% \mathrm{RH}$ for $L$. pubescens, and at $28.3^{\circ} \mathrm{C}$ and $37.7 \% \mathrm{RH}$ for $L$. dentata. This finding indicates that the two species may have different optimum weather conditions for peak nectar secretion.

\section{Honey production potentials of the species}

The mean maximum volumes of accumulated nectar/flower recorded were $0.68 \pm 0.19 \mu \mathrm{L}$ at 18:00 for L. dentata, and $0.50 \pm 0.24 \mu \mathrm{L}$ at 15:00 for $L$. pubescens. Considering the mean maximum nectar volumes and their respective nectar sugar concentrations of $32.36 \%$ for $L$. pubescens and $31.71 \%$ for L. dentata; a mean of $0.22 \mathrm{mg}$ and $0.16 \mathrm{mg}$ of nectar sugar/flower were recorded for $L$. dentata and $L$. pubescens, respectively.

The mean numbers of spikes/plant, were 204 for $L$. dentata and 277 for $L$. pubescens, and the mean numbers of flowers per spike, were 90.87 and 64.08 for $L$. dentata and $L$. pubescens, respectively. Hence, the mean numbers of flowers/ plant were estimated to be 18,537 for L. dentata, and 17,750 for $L$. pubescens. Based on the mean numbers of flowers/plant; the estimated amounts of nectar sugar per plant were then calculated to be $4078.14 \mathrm{mg}$ and $2840 \mathrm{mg}$ for L. dentata and $L$. pubescens, respectively. Assuming 18\% of honey is water, from the average amount of nectar sugar recorded by the individual plants, $L$. dentata and $L$. pubescens can produce $4973.34 \mathrm{mg}$ and $3463.41 \mathrm{mg}$ honey/plant.

Based on the mean canopy diameter of each species (Tab. 1) and the space required between plants; the numbers of plants estimated to grow per hectare of land were 10249.8 and 6936.6 for $L$. dentata and $L$. pubescens, respectively. According to the above-described computations, the expected nectar sugar for $L$. dentata and L. pubescens were $41.8 \mathrm{~kg} / \mathrm{ha}$ and $19.7 \mathrm{~kg} / \mathrm{ha}$, respectively. Consequently, $L$. dentata and L. pubescens can yield an estimated $51.0 \mathrm{~kg}$ honey/ ha and $24.1 \mathrm{~kg}$ honey/ha, respectively. This means that the expected honey production potential of $L$. dentata is twice that of $L$. pubescens.

\section{DISCUSSION}

\section{Floral morphology and phenology}

The floral morphologies of the two lavender species appear suited to the body size of small insects

Table 1.

Plant and flower morphometric parameters of Lavandula pubescens and Lavandula dentata (the mean values are given \pm SD)

\begin{tabular}{lccccc}
\hline Species & $\begin{array}{c}\text { Plant height } \\
(\mathbf{c m})\end{array}$ & $\begin{array}{c}\text { Crown height } \\
\mathbf{( c m )}\end{array}$ & $\begin{array}{c}\text { Crown } \\
\text { diameter } \\
(\mathbf{c m})\end{array}$ & $\begin{array}{c}\text { Crown } \\
\text { volume }\left(\mathbf{m}^{3}\right)\end{array}$ & $\begin{array}{c}\text { No. of } \\
\text { flowers / } \\
\text { plant }\end{array}$ \\
\hline L. dentata & $85.7 \pm 17.5^{\mathrm{a}}$ & $41.4 \pm 9.4^{\mathrm{a}}$ & $74.7 \pm 28.5^{\mathrm{a}}$ & $0.09 \pm 0.1^{\mathrm{a}}$ & 18537 \\
\hline L. pubescens & $53.0 \pm 20.8^{\mathrm{b}}$ & $27.6 \pm 10.0^{\mathrm{b}}$ & $97.4 \pm 23.8^{\mathrm{b}}$ & $0.04 \pm 0.1^{\mathrm{b}}$ & 17750 \\
\hline $\mathrm{t}$-value & 8.701 & 7.383 & -3.324 & 3.975 & - \\
\hline P-value & 0.000 & 0.000 & 0.003 & 0.000 & - \\
\hline
\end{tabular}

The means followed by the same letter within columns are not significantly different at $\alpha=0.05$. $N=63$ for Lavandula dentata and $N=47$ for $L$. pubescence 


\section{J. APCL. SCL. VOL. 59 NO. 22015}

such as honeybees. The insects are able to easily alight on flowers and collect nectar. The corolla tube of L. dentata is relatively short (4 - $5 \mathrm{~mm}$ ); so, the smallest indigenous honeybee (Apis mellifera jemenitica), with a proboscis length of $5.277 \pm$ $0.210 \mathrm{~mm}$ (Ruttner, 1988), can easily access the nectar. The corolla tube of $L$. pubescens is relatively longer than the proboscis lengths of indigenous honeybees. The bees, however, were observed be packed into their pollen baskets. The visiting of honeybees may still provide a sufficient level of pollination via mechanical dislodging and the movement of the proboscis through the corolla tubes.

In terms of flower phenology, interestingly, only a few (5 - 7) flowers open at a time per spike, and when these flowers have almost wilted, other new flower buds prepare to open. This sequential opening of a few flowers at a time might be an adaptation of

Table 2.

Daily dynamics of nectar production in flowers of the two lavender species

\begin{tabular}{|c|c|c|c|c|c|c|c|c|}
\hline \multirow[b]{3}{*}{ Species } & \multirow[b]{3}{*}{ No. } & \multicolumn{5}{|c|}{$\begin{array}{c}\text { The mean nectar volume }(\mu \mathrm{L}) \text { accumulated in a flower at different } \\
\text { times of the day (local time }=\mathrm{GMT}+3 \mathrm{~h} \text { ) }\end{array}$} & \multirow[b]{3}{*}{ F-value } & \multirow[b]{3}{*}{ P-value } \\
\hline & & 06:00 & 09:00 & $12: 00$ & $15: 00$ & $18: 00$ & & \\
\hline & & (a) & (b) & (c) & (d) & (e) & & \\
\hline L. pubescens & 90 & $0.28 \pm 0.19^{a}$ & $0.41 \pm 0.25^{\mathrm{ab}}$ & $0.46 \pm 0.23^{b}$ & $0.50 \pm 0.24^{b}$ & $0.41 \pm 0.21^{c}$ & 12.597 & $<0.001$ \\
\hline Rate of secretion* & & $a=0.28$ & $b-a=0.13$ & $c-b=0.05$ & $d-c=0.04$ & $e-d=-0.09$ & & \\
\hline L. dentata & 90 & $0.35 \pm 0.15^{a}$ & $0.40 \pm 0.14^{a}$ & $0.53 \pm 0.19^{b}$ & $0.64 \pm 0.20^{c}$ & $0.68 \pm 0.19^{c}$ & 62.645 & $<0.001$ \\
\hline Rate of secretion* & & $a=0.35$ & $b-a=0.05$ & $c-b=0.13$ & $d-c=0.11$ & $e-d=0.04$ & & \\
\hline \multicolumn{9}{|c|}{ The mean for the species } \\
\hline \multirow{2}{*}{$\begin{array}{l}\text { Nectar volume } \\
\text { per flower }(\mu L)\end{array}$} & No. & L. pubescens & L. dentata & & & & t-value & P-value \\
\hline & 450 & $0.41 \pm 0.24^{a}$ & $0.52 \pm 0.22^{b}$ & & & & -6.991 & $<0.0001$ \\
\hline
\end{tabular}

The means in the rows followed by the same letter are not significantly different at $\alpha=0.05$.

*Rate of nectar secretion is the average volume of nectar secreted during 3 hours which is calculated as the difference between the two consecutive measurements.

Table 3.

Correlation of temperature and relative humidity with nectar volume measurements for the two lavender species

\begin{tabular}{lllllll}
\hline \multirow{2}{*}{ Variable } & \multirow{2}{*}{ By variable } & \multirow{2}{*}{ Count } & \multicolumn{2}{c}{ Correlation } & \multicolumn{2}{c}{ P-value } \\
\cline { 4 - 7 } & & & L. pubescens & L. dentata & L. pubescens & L. dentata \\
\hline Temperature $\left({ }^{\circ} \mathrm{C}\right)$ & Nectar in $\mu \mathrm{L}$ & 450 & 0.2360 & 0.2796 & 0.0001 & $<0.0001$ \\
Relative humidity & Nectar in $\mu \mathrm{L}$ & 450 & -0.0826 & 0.1373 & $=0.080$ & $=0.004$ \\
\hline
\end{tabular}

collecting nectar, which might have been with the help of the capillary action of the style. Similarly, despite their short proboscis lengths, honeybees managed to draw nectar as far as $11.65 \mathrm{~mm}$ by taking advantage of the capillary action of the style to access the corolla tube of cardamom (Venkateshalu and Vivek, 1997). Nonetheless, honey bees prefer to collect nectar (greater frequency) from $L$. dentata than from L. pubescens flowers (personal observation), possibly because the corolla tube length matches well with their proboscis length. The location of nectar and the proboscis length are known to be important factors in determining the associations between flowers and flower-visiting insects (Martina et al., 2009). In general, the pollen grains of the two species are not easily dislodged and are not dusted onto the bodies of honeybees to the species for the economic allocation of sufficient synthesised energy (in the form of nectar) to attract flower visitors. The sequential opening might also act to minimise competition among flowers for pollinators. The display of only a few flowers at a time by plants, has been reported to impart an advantage in terms of maximising pollen export (Klinkhamer et al., 1994). Plants that display greater numbers of flowers at a time may attract a greater number of pollinators but are reported to experience substantial pollen transport losses (Biernaskie and Cartar, 2004). In this context, both species might be well adapted for efficient pollen transfer.

The individual flowers of each species are present for a considerable length of time ( $9 \mathrm{~h}$ and $12 \mathrm{~h}$ in $L$. pubescens and $L$. dentata, respectively). Moreover, their nectar secretion dynamics follow 
the life span of the flower. Floral longevity has been reported to play an important role in reproductive ecology, influencing the total number of visits by pollinators and the amount and diversity of pollen received (Ashman and Schoen, 1996).

\section{Blooming season distribution}

The flowering of the two species is very long and lasts for approximately two to three months. During this time, the spikes continue to grow and a few flowers open at a time. This flowering strategy is advantageous to the plant for resource distribution and for effective pollination. The elongated flowering period is also useful in relation to beekeeping, in that the bees have considerable time to collect and store nectar. The contribution of a longer flowering period to increased honey production has been well-documented (Burge et al., 2006). The overlap in the flowering duration and the periods of peak flowering in the two species might be attributed to their similar physiological responses to environmental stimuli.

\section{Morphometric values}

Despite sharing similar habitats, the morphometric values: plant height, crown height, and canopy volume, which are measures of biomass, were generally greater for $L$. dentata compared to $L$. pubescens. The higher number of flowers per spike in L. dentata than in L. pubescens may be associated with the higher biomass of the former species. Furthermore, the current study revealed a strong positive correlation between the evaluated morphological parameters and the number of flowers, which is in agreement with Zhang et al. (2013), who reported a significant positive correlation between the number of flowers and the aboveground biomass in Stellera chamaejasme. The higher biomass of $L$. dentata is expected to supply greater nectar and pollen resources, which means attracting a greater number of flower visitors.

\section{Amount and dynamics of nectar secretion and effect of weather conditions}

Even though a single flower was used for a one time measurement, from the mean accumulated volume of nectar recorded for different flowers at different times of the day, it was clear that both species continue to secrete nectar throughout the day, for approximately $9 \mathrm{~h}$ and $12 \mathrm{~h}$ for $L$. pubescens and L. dentata, respectively. Under natural conditions, while the flowers remain open, it is expected that flower visitors can consume the nectar. Therefore, for each species, the increases in the amounts of nectar recorded over time in caged flowers (Tab. 2) indicates the additional amount of nectar secreted by the flowers during the interval between two consecutive measurement times. Generally, the mean volume of nectar secreted per flower of $L$. dentata was significantly $(P<0.0001)$ higher than the volume of nectar secreted per flower of $L$. pubescens. At the end of the flower stage, L. dentata had more accumulated nectar than L. pubescens (Tab. 2). The mean amount of nectar sugar/flower/day and nectar sugar concentration recorded in this study for both species, were lower than the average values recorded for Lavandula latifolia under Southern Spanish Mediterranean scrubland conditions (Herrera, 1985). It should be noted, that the volume of nectar recorded for L. latifolia was smaller than L. dentata but equal with $L$. pubescens. Despite the arid environmental conditions of the study area, both species produced a comparable volume of nectar.

Inaddition, themaximumnectar-secretionattainment time varied between the two species (Tab. 2). This variation may be related to the difference in the life span of their flowers. The decline in the amount of nectar in bagged $L$. pubescens flowers after 15:00 might be attributable to the reabsorption of secreted nectar by the plants. The reabsorption and modification of unconsumed nectar is considered a strategy for the partial recovery of the energy cost invested in nectar production for numerous species (Nepi and Stpiczyńska, 2008; Nepi et al., 2011).

The mean temperature $\left(35.7^{\circ} \mathrm{C}\right.$ for L. pubescens and $28.3^{\circ} \mathrm{C}$ for $L$. dentata) and relative humidity $(28.7 \%$ for $L$. pubescens and $37.7 \%$ for $L$. dentata) at which the highest nectar volumes were recorded, might be considered the optimal weather conditions for maximum nectar production and effective pollination for each species. Although the two species have overlapping flowering periods, they have different optimum humidity and temperature levels for the secretion of maximum nectar. These factors may be an adaptation of the two co-existing and co-flowering species to minimise competition for pollinators. The temporal partitioning of floral resources as a mechanism of minimising competition for pollinators has been well documented for several sympatric and co-flowering plant species (Ollerton and Lack, 1992; Stone et al., 1998).

The positive correlations between the amount of nectar and the air temperature of the area might indicate the adaptation of these species to warm climatic conditions. Similarly, positive correlations between ambient temperature and the 
nectar secretion amount, have been recorded for numerous nectar-secreting species e.g., Trifolium repens, (Jakobsen and Kristjansson, 1994), Thymus capitatus, (Petanidou and Smets, 1996), and Ziziphus spina-christi, (Nuru et al., 2012).

\section{Honey production potential}

Under natural conditions, the amounts of honey obtained per ha of land $(51.0 \mathrm{~kg} / \mathrm{ha}$ from $\mathrm{L}$. dentata and $24.1 \mathrm{~kg} / \mathrm{ha}$ from $L$. pubescens) are relatively greater than the honey production values of 20.14 $\mathrm{kg} / \mathrm{ha}$ and $23.02 \mathrm{~kg} / \mathrm{ha}$ recorded for Nepeta deflersiana and Otostegia fruticosa, respectively (Al-Ghamdi et al., 2015 unpublished).

In addition, because lavender honey is a specialty item, its high market price as well as the possibility of enhancing the vegetative performance of lavender species with improved agronomic practices, may indicate additional premium production potentials for these lavender species. In this regard, further research on the potential for the planting and adaptation of these species to both degraded lands and backyards, with the integration of beekeeping, would be useful for the assessments of their ecological and economic values. In both species, flowers were observed to open in succession (day and night) without having a definite time of opening. In this regard, further observations on the presence of nocturnal visitors (if any) might be important.

\section{CONCLUSIONS}

Based on the dynamics and the amounts of nectar secreted per flower and per plant, the two lavender species can be considered as potential honey source plants for the region. It should be noted, that under the study area conditions, the honey production potential of $L$. dentata is relatively better than that of $L$. pubescens. In general, the importance of the species is significant not only in terms of serving as sources of specialty honey but also in terms of their ecological values. These values may be attributed to the ability of these species to thrive under low moisture and poor soil conditions and to contribute to ecosystem functioning and the maintenance of insect diversity under these conditions.

\section{ACKNOWLEDGMENTS}

The authors are grateful to the Deanship of Scientific Research and College of Food and Agricultural Science Research, King Saud University Riyadh, for providing research support.

\section{REFERENCES}

Ashman T., Schoen D. J. (1996) Floral Longevity: Fitness Consequences and Resource Costs. In: Lloyd D.G., Barrett S. C. H. (Eds.) Floral biology. Studies on floral evolution in animal-pollinated plants. Chapman and Hall. New York: 112-139.

Azcón R., Barea, J. (1997) Mycorrhizal dependency of a representative plant species in Mediterranean shrublands (Lavandula spica L.) as a key factor to its use for revegetation strategies in desertification-threatened areas. Applied Soil Ecology 7 (1): 83-92. DOl: 10.1016/ S0929-1393(97)00013-9

Biernaskie J. M., Cartar R. V. (2004) Variation in rate of nectar production depends on floral display size: a pollinator manipulation hypothesis. Functional Ecology 18: 125-129.

Boning C. R. (2010) Florida's Best Herbs and Spices: Native and Exotic Plants Grown for Scent and Flavor. Pineapple Pr Inc. Sarasota. 229 pp.

Burge G., Bycroft B., Leach M. (2006) Extending the flowering period of Manuka. New Zealand Institute for Crop and Food Research Limited. Palmerston North. 15 pp. Available at: http://maxa.maf.govt.nz/sff/about-projects/ search/03-055/extending-flowering-of-manuka.pdf

Chu C. J., Kemper K. J. (2001) Lavender (Lavandula spp.) The Longwood Herbal Task Force and The Center for Holistic Pediatric Education and Research). 32 pp. Available at: http://www.longwoodherbal.org/lavender/ lavender.pdf

Crane E., Walker P., Day R. (1984) Directory of Important World Honey Sources. International Bee Research Association. London. 384 pp.

El-Karemy Z. A., Zayed K. M. (1 992) Distribution of Plant Communities Across Al Abna Escarpment, SW Saudi Arabia. Phyton (Horn, Austria) 32 (1): 79-101.

Forler S. (2013) Lavender Honey. Honey Traveler. Available at: http://www.honeytraveler.com/singleflower-honey/lavender-honey/

Herrera J. (1985) Nectar secretion patterns in Southern Spanish Mediterranean Scrublands. Israel Journal of Botany 34: 47-58 
Jakobsen H., Kristjansson K. (1994) Influence of temperature and floret age on nectar secretion in Trifolium repens L. Annals of Botany 74: 327-334.

Kim M. S., Kim S. H., Han J., Kang M. S., Park Y. K. (201 1) Honeybee visit and nectar secretion characteristics of the Chinese Hawthorn Crataegus pinnatifida Bunge. Journal of Apiculture. The Apicultural Society of Korea 26(1): 11-14.

Klinkhamer P. G. L., de Jong T. J., Metz A. J. (1994) Why plants can be too attractive - a discussion of measures to estimate male fitness. Journal of Ecology 82: 191 194.

Lalande B. (1984) Lavender, lavandin and other French oils. Perfumer and Flavorist 9: 117-121.

Lis-Balchin M. (2003) Lavender: The Genus Lavandula. CRC Press. London, UK. 296 pp. Available at: http://books.google.ca/books/about/Lavender. html?id=TmvkY60iESkC

Martina S., Klinkhamer P. G. L., Waser N. M., Stang I., Meijden E. (2009) Size-specific interaction patterns and size matching in a plant - pollinator interaction web. Annals of Botany 103: 1459-1469. DOl: 10.1093/aob/mcp027

Miller A. G. (1985) The genus Lavendula in Arabia and Tropical NE Africa. Notes Royal Botany Garden. Edinburgh 42 (3): $503-528$

Nagy Z. (2002) Egyrenépszerübb növényünk a facélia III. Méhészet 50(4): 22.

Nepi M., Stpiczyńska M. (2008) The complexity of nectar: secretion and resorption dynamically regulate nectar features. Naturwissenshaften 95: 177-184.

Nepi M., Cresti L., Guarnieri M., Pacini E. (201 1) Dynamics of nectar production and nectar homeostasis in male lowers of Cucurbita pepo L. International Journal of Plant Science 172(2): 183-190. DOl: 10.1086/657648

Nuru A., Awad M. A., Al-Ghamid A. A., Alqarni, A. S., Radloff S. E. (2012) Nectar of Ziziphus spina-christi (L.) WILLD (Rhamnaceae): dynamics of secretion and potentials for honey production. Journal of Apicultural Science 56 (2): 49-59. DOl: 10.2478/v10289-012-0023-9
Ollerton J., Lack A. J. (1992) Flowering phenology: an example of relaxation of natural selection? Trends in Ecology and Evolution 7: 274-276.

Petanidou T., Smets E. (1996) Does temperature stress induces nectar secretion in Mediterranean plants? New Phytologist 133: 513-518.

Rahman M. A., Mossa J. S., Al-Said M. S., Al-Yahya M. A. (2003) Medicinal plant diversity in the flora of Saudi Arabia 1: a report on seven plant families. Fitoterapia 75: 149-161.

Ruttner F. (1 988) Biogeography and taxonomy of honey bees. Springer-Verlag. Berlin, Germany. 284 pp.

SAS (2002) SAS Institute Inc. JMP-5 Statistical Software. Version 5. Cary, NC, USA.

Stone G. N., Willmer P. G., Rowe J. A. (1998) Partitioning of pollinators during flowering in an African Acacia community. Ecology 79: 2808-2827.

Szabo T. I., Najda H. G. (1 985) Flowering, nectar secretion and pollen production of some legumes in the Peace River Region of Alberta, Canada. Journal of Apicultural Research 24(2): 102-106.

Venkateshalu V. V. B., Vivek H. R. (1997) Significance of style in cardamom corolla tubes for honey-bee pollinators. Current Science 73(3): 287-290.

Welsh C. (1995) Three essential oils for the medicine cabinet. Alternative Health Practitioner 3: 11-15.

Wyatt R., Broyles S. B., Derda G. S. (1992) Environmental influences on nectar production in milkweeds (Ascelapias syriaca and A. exaltata). American Journal of Botany 79: 636-642.

Zhang Q., Zhao C., Dong X., Ma X., Hou Z., Li Y. (2013) Relationships between flower size, flower number, and plant size of Stellera chamaejasmem population along an altitude gradient of degraded alpine grassland in Northwest China. Chinese Journal of Plant Ecology 32(12): 3160-3166.

Zsidei B. (1993) Méhészeti ismeretek. Fazekas és fiai nyomdája. Szarvas. 613 pp. 